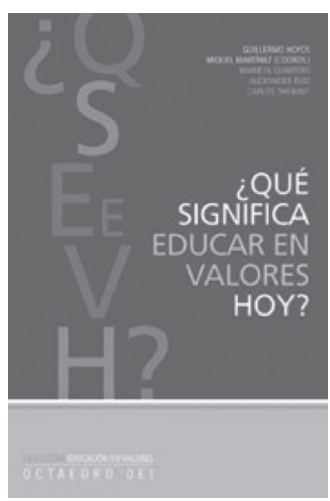

\title{
Reseña del libro \\ ¿Qué significa educar en valores hoy?, de Guillermo Hoyos-Vásquez y Miquel Martínez (coords.)
}

En el prefacio, Francisco Piñón, secretario de la OEI, presenta este libro como parte de una colección que pretende ofrecer a los educadores y a quienes reconozcan en la dimensión política y moral de la formación de las nuevas generaciones la oportunidad para ahondar - desde el contexto iberoamericano y con rigor académico - en la apuesta de la OEI por una educación para la ciudadanía activa, a partir de una formación en valores surgida en la interacción con otros, que le permita a la persona aprender a apreciarlos, a denunciar cuando no están presentes y a construir su matriz personal.

En la presentación, los coordinadores resaltan que la colección que conforma el libro adhiere a los objetivos de la OEl en el Programa de educación en valores y democracia, desde un sólido soporte teórico y con un cuidadoso tratamiento pedagógico que le permite ser, a la vez, una posibilidad de aprendizaje de elementos teóricos y también de estrategias que fortalezcan la práctica pedagógica de los profesores de Iberoamérica que se arriesguen a superar la mera transmisión de contenidos y le apuesten a la educación en valores en y para las sociedades plurales.

La apertura al tema, de la mano de Guillermo Hoyos-Vásquez y Miquel Martínez, es contundente en la intención de plantear los escenarios de reflexión sobre la provocación que encarna la pregunta ¿qué significa educar en valores hoy? En primer lugar, nos

Para citar este artículo / To cite this article / Pour citer cet article / Para citar este artigo

Arias-Delgado, L. (2014). Reseña del libro ¿Qué significa educar en valores hoy?, de Guillermo Hoyos-Vásquez y Miquel Martínez (coords.). magis, Revista Internacional de Investigación en Educación, 6 (13), 189-191. 
invita a preguntarnos por el tipo de sociedad a la que apuntamos con nuestras prácticas pedagógicas. La apuesta de los autores es una sociedad más democrática, pluralista y solidaria. Desde este punto de partida empiezan a marcar las coordenadas de una cartografía que nos permita contribuir a "formar ciudadanas y ciudadanos auténticos que sepan asumir conscientemente los retos de la globalización y puedan comprometerse en la construcción de un mundo más justo, más incluyente, equitativo y multicultural" (p. 15).

Como lo señala Miquel Martínez en el primer capítulo, "educar en valores es crear condiciones pedagógicas y sociales", necesarias para que haya un auténtico proceso de desarrollo y construcción personal, desde la autonomía y la comprensión crítica. Implica un cambio en la forma de afrontar la vida de aula, en las funciones de los actores del proceso educativo, en los objetivos de la enseñanza, en los escenarios de la educación y en los aspectos curriculares. Educar en valores necesita "motivar y entrenar para la implicación en proyectos colectivos" que busquen el bien común, de manera que, en condiciones como la pluralidad y diversidad cultural, podamos superar las miradas absolutistas y relativistas y entender que un estilo de vida democrático requiere alcanzar consensos desde un enfoque intercultural que favorezca la inclusión social. Para educar en valores también se necesita transformar el papel del maestro y atender a su formación, brindarle oportunidades para acceder a los ámbitos de la política, de la formación científica, de la economía y de la ética, además de los contenidos conceptuales y procedimentales imprescindibles para "el cultivo de la humanidad" (Nussbaum, 2005) en una sociedad que necesita buenos ciudadanos, pero también ciudadanos buenos, capaces de responder a retos como transitar de la información al conocimiento o superar el individualismo y construir su propio yo en interacción con los otros.

Los aportes de Miquel Martínez a la colección reúnen las propuestas del grupo de investigación en educación moral (GREM) de la Universidad de Barcelona, del cual es miembro y dan cuenta de su amplio recorrido por los temas de la formación del profesorado, de la práctica escolar y de la investigación y política universitaria. El modelo de formación en valores que presenta es una apuesta que circula entre el ámbito de los fines generales y el de las técnicas y procura integrar la construcción de la personalidad moral con atención a las dimensiones racional, afectiva y volitiva de la persona y a la aprehensión de un conjunto de valores deseables. Este modelo de "aprendizaje ético" va acompañado de una serie de criterios de actuación del educador que apuntan al ejercicio de la autonomía personal, del respeto a la diferencia y del cultivo del diálogo, que permitan alcanzar el objetivo de la educación en valores:

[...] la formación de personas autónomas y dialogantes, dispuestas a implicarse y comprometerse en una relación personal y en una participación social basadas en el uso crítico de la razón, la apertura a los demás y el respeto a los derechos humanos (p. 42).

En el segundo capítulo, "Ética y educación en valores", Guillermo Hoyos-Vásquez nos conduce a reflexionar sobre si la moral se puede y debe enseñar y cómo y para qué hacerlo, con el fin de que nos lleve a encontrar el sentido fundamental de la construcción comunicativa de una ética para ciudadanos. En la introducción al capítulo hace una presentación de la situación de deslegitimación del Derecho Internacional y de la debilidad de los argumentos morales por situaciones como la guerra. Una vez más, el filósofo recurre a Kant y su sentido utópico de la paz. El "ino debe haber guerra!" es presentado desde el deber ser, como la solución a la situación que ya en 1797 aquejaba al mundo. Cita a Kant a partir de La paz perpetua para señalar el deber de razón práctica de buscar la paz. También hace evidente que las diversas crisis globales han despertado una solidaridad global y, en este punto de la reflexión, nos interpela: "¿Puede la educación de las generaciones presentes fortalecer este sentido de solidaridad global, expresados ya en los inicios de la modernidad como 'sentimiento de humanidad' y 'moral universalista'?" (p. 49). El filósofo dibuja el camino de la reflexión a partir de mirar los valores en sí mismos y reflexionar sobre su origen, naturaleza, constitución y modo de surgir, para vincularlos con el proceder de los ciudadanos. Para dilucidar la relación de los valores con la acción humana recurre a Jürgen Habermas y su teoría del actuar comunicacional, pues en el acto comunicativo es en donde se hacen explícitos los valores y llegamos a comprender al otro, aun sin estar de acuerdo, a partir del reconocimiento en su diferencia como interlocutor válido; una validez enunciada con pretensiones de veracidad desde el mundo objetivo, de rectitud desde el mundo social y de credibilidad en el mundo subjetivo. La intersubjetividad nos permite acercar las fronteras entre la experiencia individual y las formas de vida colectiva; entonces, podemos decir con el profesor que la capacidad para aplicar los ideales y propósitos morales en la vida diaria es susceptible de ser cultivada mediante prácticas educativas discursivas, a partir, por ejemplo, de ejercicios de discusión y solución de dilemas morales en el aula de clases.

Los capítulos que siguen, "¿Qué no es educar en valores?", "El caso de la responsabilidad" y "¿Qué significado tiene investigar sobre formación en valores?", 
complejizan lo que significa una educación en valores en el siglo XXI. En el primero, el doctor en Filosofía y catedrático de la Universidad Carlos III de Madrid, Carlos Thiebaut, nos propone una mirada analítica sobre la influencia que tienen las creencias sobre el sentido de la moral en la educación en valores. El texto nos lleva por las concepciones intuicionistas - que consideran a los valores como entidades con una existencia objetiva, lo cual imposibilita su enseñanza—, la concepción subjetivista — que asume los valores como una manifestación emotiva frente a los nuestros actosy, por último, la visión pragmatista — que ve los valores como parámetros de los juicios que realizamos y no deben ser desligados de las condiciones y manifestaciones sociales y que relaciona, en una buena parte del texto, con la responsabilidad-.

En el último capítulo, los profesores e investigadores colombianos Marieta Quintero y Alexander Ruiz buscan responder a la pregunta "¿Qué significado tiene investigar sobre formación en valores?". Nos conducen hacia una mirada principalmente empírica sobre los alcances de la investigación en valores en los contextos de formación. Parten de la concepción de que el escenario moral es la vida misma, lo que justifica abordajes teóricos y empíricos. En el segundo aparte, prueban la importancia del lenguaje a partir de la problematización de las justificaciones que sirven como punto de partida de algunas experiencias de investigación y que dan cuenta del saber moral de los docentes y los profesores en formación involucrados en las investigaciones. Así mismo, problematizan sus apreciaciones sobre las esferas de lo político y lo moral, lo que permite entender las percepciones morales acerca de sí mismo y de los otros. Este capítulo nos interpela sobre:

¿Cómo orientar procesos de formación moral en contextos de guerra y paz? ¿Cómo puede un maestro educar a sus estudiantes, en contextos extremadamente conflictivos, para actuar moralmente en el conjunto de su vida? ¿Cómo apostarle en serio a la formación de ciudadanos bajo condiciones de violencia y desesperanza? (p. 116).

Y los retos que, en términos de formación del profesorado, pueden significar.

Es claro que esta colección bajo el título de ¿Qué significa educar en valores hoy? es una referencia obligada a la hora de asumir el reto de la formación que supere la mera trasmisión de contenido y que cumpla con su cometido político en la formación de ciudadanías participativas capaces y comprometidas en la construcción del destino de la humanidad.

\section{Sobre la autora}

Liliana Arias-Delgado es estudiante del Doctorado en Ciencias Sociales y Humanas de la Pontificia Universidad Javeriana. Sus líneas de docencia e investigación se centran en estudios sobre la ética y la educación y las transformaciones de la educación en la sociedad de la información.

\section{Referencias}

Nussbaum, M. (2005). El cultivo de la humanidad. Una defensa clásica de la reforma en la educación liberal. Barcelona: Paidós.
Descripción del artículo | Article description | Description de l'article | Artigo descrição

Reseña del libro ¿Qué significa educar en valores hoy? de Guillermo Hoyos-Vásquez y Miquel Martínez (coords.)

Hoyos-Vásquez, G., \& Martínez-Quintero, M. (coords.) (2004). ¿Qué significa educar en valores hoy? Barcelona: Octaedro-OEI. 128 pp. ISBN: 84-8063-698-X 